\title{
Application AHP-PROMETHEE Technic for Landfill Site Selection on Based Assessment of Aquifers Vulnerability to Pollution
}

\author{
Parisa Mohammadi Seif Abad ${ }^{1}$ - Ebrahim Pazira ${ }^{1} \cdot$ Mohammad Hassan Masih Abadi ${ }^{2}$ Parviz Abdinezhad $^{3}$
}

Received: 24 May 2017 / Accepted: 7 December 2020 / Published online: 16 March 2021

(c) The Author(s) 2021

\begin{abstract}
Choosing a suitable location for the disposal of municipal solid waste is an important environmental problem. Thus, locating a municipal solid waste landfill has been very important. Leachate from the solid waste landfill causes the contamination of groundwater. However, the process is complicated and is based on qualitative and quantitative criteria. Therefore, in this paper, a hybrid approach for determining the optimal location of a municipal solid waste landfill has been presented. Additionally, the present study attempts to evaluate the potential of aquifer contamination vulnerability on the proposed landfill sites using a DRASTIC model of Plain Zanjan and provide a zoning map of vulnerable areas. In this study, the DRASTIC model for aquifer vulnerability mapping is used. This model consists of seven hydrogeological parameters effective in contaminating the aquifer. The parameters appear in the GIS software as seven layers on which the analysis is performed. Considering the map of aquifer vulnerability and with regard to the potential aquifer contamination at various areas, it is possible to determine a suitable site for the landfill. At present, about $49.03 \%$ of the aquifers are in average vulnerability situation; by considering them, a suitable site for the landfill can be determined. Accordingly, the considered criteria were determined by AHP method; the weights of the layers were determined, and then the appropriate places were classified into three classes, high, moderate or low, using GIS software. Finally, zones located in the high classes were selected as the best locations for waste disposal by the PRPMOTHEE method, by taking into account the scientific limitations and conditions of the area. The results showed that proposed methods in this paper can be suitable to determine appropriate option for waste disposal. In the future, there can be a lot of studies for modeling to choose a suitable landfill due to some soil characteristics and applying other models of pollution to groundwater in the region.
\end{abstract}

Keywords Solid waste $\cdot$ DRASTIC model $\cdot$ Aquifer vulnerability $\cdot$ Hydrogeological $\cdot$ AHP $\cdot$ PROMETHEE

\section{Introduction}

During the twentieth century, especially after World War II, planet Earth has experienced a huge population explosion. Rapid technological advances, which have created a new culture of production and consumption, have led to the increasing proliferation of the number of industrial and atomic municipal solid waste landfills. Many of the health

Ebrahim Pazira

Ebrahimpazira@gmail.com

1 Department of Soil Science, Science and Research Branch, Islamic Azad University, Tehran, Iran

2 Soil and Water Research Institute, Tehran, Iran

3 Soil Conservation and Watershed Management Research Department, Zanjan Agricultural and Natural Resources Research and Education Center, AREEO, Zanjan, Iran problems of developing countries originate from these waste products, which are considered to be the most hazardous environmental pollutants. Solid waste management is one of the most critical environmental problems around the world. Waste management includes waste reduction, reuse, material cycle, energy recovery, incineration and burial in landfills (Abdoli (2005)).

The sharing in the responsibility of any of these methods regarding the disposal of waste varies and depends directly on the level of technology and the progress of a particular country. Despite efforts to reduce waste production from the source, recycle and recovery, large volumes of waste generated will be returned to the environment in the form of landfills. Currently, waste burying in landfills is the most dominant solid waste management method because of the simplicity and low cost compared to other methods (Kim and Owens 2009). 
Also, part of the material obtained from other disposal methods, such as ash resulting from the incineration, composting excess and nonrecyclable materials, should eventually be buried in an adequately safe way. A waste management system is sustainable when it is environmentally controllable, socially acceptable and economically affordable (Morrissey and Browne 2004). Therefore, when locating a landfill site, many criteria in the environmental, sociocultural and economic-technical gastric should be considered. As a result, the decision making for a new location of a landfill will be difficult and overwhelming (Chang et al. 2008). The criteria needed in a suitable location for the disposal of waste are mainly based on the potential for pollution generating due to waste disposal and the knowledge of the interactions between land quality and possible risks. Studies of the locations of municipal waste landfills, in principle, are dependent on the natural and legal conditions of any region.

Therefore, a proper burial place should include environmental criteria and safety features, which provide the ability to separate the waste in such a manner that a significant problem is not created for people or the environment (Manoliadis et al. 2001). If the location is selected properly, it will be effective in reducing the costs of design, construction and operation, as well as minimizing the environmental impact (McNally 2002).

For this reason today, a lot of attention is given to the industrial and municipal waste landfill as one of the main sources of water, air and soil contamination (Sener et al. 2011). The most important environmental problem of municipal waste landfill is leachate, which eventually causes contamination of groundwater (Naqa (2004)). Leachate is formed due to penetration of rainwater and waste moisture in the landfill. During its formation, organic and nonorganic materials are moved from the waste to the fluidized bed, which endangers the groundwater at the landfill site (Hasar et al. 2009).

Therefore, groundwater contamination is one of the issues that arise while locating a municipal solid waste landfill. In general, waste disposal areas should be designed not to create groundwater contamination as much as possible. If it does happen, the contaminated area should be identified and reviewed immediately. Usually, solid waste landfill sites must be located in a place where waste materials are fully away from groundwater systems. There are various methods for locating landfill sites, and in some, GIS is used (Zamorano et al. 2008).

Therefore, many criteria in environmental, social, cultural, and technical-economic fields should be considered in locating a dump. This has made it difficult and tedious to decide on a new excavation site. One of the most important criteria to locate landfills is considering the nonpollution of surface and groundwater. After landfill, waste produces highly toxic and hazardous substances called leachate which can contaminate surface and groundwater resources. For this reason, natural or artificial liners and leachate collection systems are used in designing the embankments.

Unfortunately, due to high cost, it is impossible to use such a design for gravel everywhere, especially in developing countries. Many applied rubbles in Iran lack required standards, despite opposition from Environment Organization. Leachate movement in these places toward groundwater can cause pollution which makes them unusable during the time.

Therefore, considering the importance of preserving water resources in our country, it is better to provide a new method to locate the landfills which emphasize maintaining the pollution of groundwater aquifers. There are several criteria to determine a landfill. One of the necessary criteria for the proper location for landfilling is mostly based on the potential for pollution due to waste disposal.

However, in none of the models presented, groundwater pollution issue was specifically addressed. Although different location laws were enacted in each country or region, these laws cannot guarantee that water resources are not polluted. Therefore, among proposed models to locate the landfills of municipal solid waste, the existence of a model which professionally and scientifically considers the risk of water pollution and the vacuum of such a model are noticeable.

On the other hand, considering the location of Iran in the arid and semiarid regions, the issue of protecting water resources, especially groundwater which is an important source of drinking water, in the country is clear. However, it is necessary to provide a model which can protect these resources from the risk of pollution as much as possible. It is also important to note that although designing enclosed landfills can prevent the spread of pollution to environment, previous research showed that no enclosed landfills are completely enclosed during the time and the possibility of spreading pollution outside the environment. Therefore, this study aims to present a new model to locate municipal waste dumps emphasizing the nonpollution of groundwater.

The criteria used for determining the appropriate location of the landfill vary in terms of the location. As such, it is better to use spatial data analysis techniques for data management. In recent years, a Geographic Information System (GIS) is used as a useful tool in land-use suitability analysis (Sumathi et al. 2008). A GIS consists of four main subsystems, namely input, storage and management, processing and analysis of data output. In each of these stages, different kinds of information are required. The advantage of using a GIS to locate a potential landfill site is that it is not only cost-effective and time-saving, but it also provides a bank of digital information to help review areas in the long term (Sumathi et al. 2008).

The DRASTIC model consists of a combining of seven hydrogeological parameters that contaminate groundwater. 
These include the depth of water, net recharge, aquifer media, soil media, topography, impact of the vadose zone, and hydraulic conductivity. These seven parameters are specified in the GIS as seven layers in which the necessary analyses are performed. Using DRASTIC parametric raster maps in the GIS, different layers can be incorporated and vulnerability mapping can be provided.

In recent years, PRPMOTHEE method has been considered as an appropriate and powerful decision-making method by the researchers in question. Because of the possibility of taking into account the constraints of the problem, allowing the use of graphical modeling and analysis of design sensitivity is simple.

Studies have been conducted in Iran and throughout the world on landfill locating. Presently, there is adequate literature in the field of groundwater vulnerability using this model. It includes the works of Stigter, Ribera, and Carvalho Dill, who evaluated aquifer vulnerability in two regions in Portugal under the impact of agricultural activities. First, they prepared the inherent vulnerability map and the especially sensitive index, which is an adjustment of the DRASTIC index.

In Iran, in many cases, the drastic method was used to prepare groundwater vulnerability maps (Salimi et al. 2014). The landfill was located in Isfahan by assessing groundwater contamination's sensitivity to leachate using the Oleckno index and GIS. For this study, the researchers examined annual rainfall, soil type and distance between the level of underground water and the bottom of the landfill. They came to the conclusion that in terms of the Oleckno index division, the burial site was placed in the good group (Salimi et al. 2014).

Then, by comparing the results of groundwater vulnerability evaluation in both regions, they concluded that the levels of nitrate contamination and salinity in the area under study are mainly controlled by two factors: (a) volume of nitrogen inputs from the surface which is dependent on the type of land use and (b) the effect of the groundwater circulation process (Stigter et al. 2006).

In another study, which was carried out for municipal solid waste landfill locating based on land classification maps and GIS, it concluded that the proposed method has had a good accuracy and can be used as a new method for locating landfills. In a research to select a suitable location for landfill using fuzzy logic (F-ANP), it was shown that the combination of fuzzy logic and ANP can provide a better idea compared to other models. Thus, this model can be used in selecting landfills in other similar places (Isalou et al. 2012).

In other study, the main purpose of this experimental study was to optimize the homogeneous composition of photons (HFO) and identify the oxidized products of ciprofloxacin degradation (CIP) and AHP-PROMEHTEE method was used. The weights given as cost criteria were considered as PROMETHEE inputs due to the pairwise comparisons from the AHP method (Nikoo et al. 2018).

The Astaneh aquifer in Gilan was prepared using this index and GIS groundwater vulnerability maps. In this study, data were collected using the library, field studies and the descriptive-analytic method. Moreover, the DRASTIC model for groundwater vulnerability mapping was used (Javadi et al. 2011).

In another study, the selection of landfill in Addis Ababa, Ethiopia, was conducted using GIS. The results of this study showed that 12 locations selected for the landfill are very suitable. After more accurate evaluation, three locations were identified to be suitable for solid waste disposal with minimal negative effects on the environment and public health, with first, second and third rank (Sulaiman et al. 2012).

During an investigation conducted in selecting locations of nondangerous waste landfills in the region of Macedonia by fuzzy logic, AHP and GIS, it was concluded that different functions of fuzzy membership are used in fuzzy theory to standardize the criteria. However, the analytic hierarchy process provides a better result for creating the relative importance of criteria (Donevska et al. (2012)).

In the study as assessment of solid waste disposal management in Malaysia, it was concluded that the use of this method for the region and improvement in the cultural, social, economic and health conditions would be appropriate and it is an essential management requirement for this area (Badgie et al. 2012).

In a research to study all scientific articles in modeling, GIS-based MCDM is used to analyze and determine appropriate landfill. The results showed that the AHP hierarchical analysis process and WLC method have the most application in multi-criteria decision making and option ranking, respectively. Criteria analysis also showed that the criteria of surface and groundwater, geology, land use, distance from fault, distance from urban areas, distance from the road, and slope are important. This field will provide the future (Ozkan et al. 2019).

In another study, by placing a set of ambiguous language terminology (HFLTS) which addresses doubts about DM preferences that are appropriate to solve location problems. The applied approach involves the process to identify suitable alternative locations for landfilling with the MCDM method due to HFLTS and GIS with the TOPSIS method. This study was conducted in Samsun, Turkey. Due to the results, studying environmental criteria along with socioeconomic measures shows better results (Ozkan et al. 2020).

However, many previous studies to locate landfills have addressed geological and soil aspects to determine land potential for contamination of groundwater resources and soil texture; however, considering these factors is qualitative, 
and in none of the cases, spreading pollution possibility to water sources was quantitatively investigated.

Therefore, in future studies, it is suggested that in addition to evaluating soil physical properties' effect on burial location, soil salinity, permeability coefficient, and hydraulic conductivity, and soil permeability in the soil profile, the permeability coefficient of flat soils and erodibility should be investigated.

The soil was assumed to be a homogeneous environment, and no changes were made to soil texture and structure to facilitate soil studies. Contrary to all assumptions, soil rarely has a uniform texture and structure, and these characteristics differ due to depth. Therefore, considering the effect of all evaluation criteria (environmental, economic, cultural and social) and simultaneously reviewing quantitative model application of pollution and then summarizing the criteria using GIS software and applying fuzzy methods and PROMETHEE, a new model will be provided to locate municipal waste landfill.

\section{Materials and Methods}

\subsection{Study Area}

The Iran Zanjan Plain in the Northwest and the East Ghizilozan River is located between geographical coordinates $47^{\circ}$ $25^{\prime}$ to $48^{\circ} 54^{\prime}$ east longitude and $36^{\circ} 27^{\prime}$ to $37^{\circ} 15^{\prime}$ north latitude. The area is located in the watershed of Zanjanrood. The area of this region is 2286 square kilometers. The average yearly rainfall is about $290.9 \mathrm{~mm}$. The maximum daily temperature in the summer is $25.8^{\circ} \mathrm{C}$ and the minimum in winter is $-1.4^{\circ} \mathrm{C}$. The average height of this area is $1665 \mathrm{~m}$. Geologically, this area is located on the Quaternary sediments and is surrounded by the Soltanieh and Tarom Mountain. These heights geologically include the Precambrian era. The position of this region is presented in Fig. 1. According to data collected, the aquifer in the area is unconfined.

In this study, by presenting the priority of options in the partial goals of decision making to locate municipal solid waste landfill and advancing the problem in parallel, separately from each other, a way was presented so that decision-makers could choose the best option in tangible conditions. Therefore, this method is mainly used to determine the priority of options in a general goal. In fact, this model is designed to solve multi-criteria problems.

The usual procedural steps to be applied in the DRASTIC model are shown in Fig. 2.

\subsection{The Importance of Locating Landfills in Zanjan}

The current solid waste collection and disposal site in Zanjan is located $17 \mathrm{~km}$ southwest of Mehtarchai River. The present method has many problems such as unpleasant odors, scattering the nylons and papers around the site, accumulation of animals and vermin, the accumulation of leachate and stench caused by fermentation and spontaneous fire on the site of waste disposal problems in the present location.

Besides, the landfill is of very low environmental quality and pollutes vital resources such as soil and water. Due to the relatively shallow depth of groundwater and the type of soil and surface deposits, the possibility of leachate infiltration into groundwater is still an important source of drinking water supply in Zanjan, as well as the pollution of river adjacent to landfill. Economically, due to the lack of recycled facilities and equipment and the lack of waste incinerators in Zanjan, as well as the issue of landfill

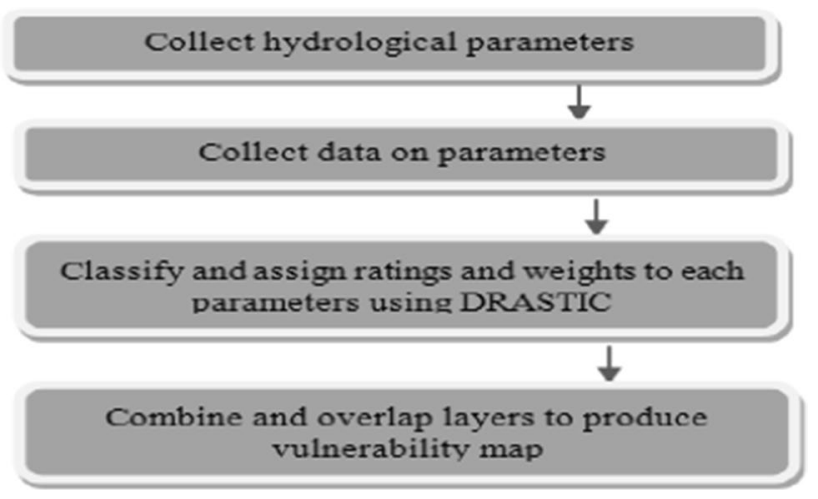

Fig. 2 DRASTIC flowchart

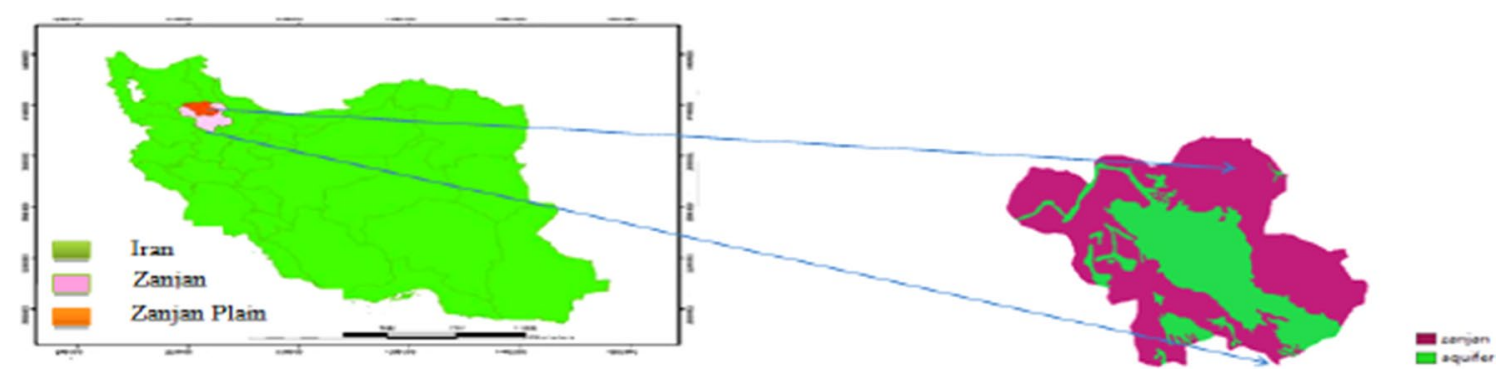

Fig. 1 Study area map 
ownership and other problems created for the residents of Mehtar village, and since solid waste is superficially buried and in Hygienic principles are not observed during burying. The new location to bury the solid waste in Zanjan is necessary.

\subsection{Information Layer}

1. Depth of water layer $(D)$ It determines the depth which the contamination must reach to become static (Rahman 2008). The deeper the water level, the more the movement time and retention of the contamination, thus increasing the attenuation capacity as in Fig. 3.

2. Net recharge $(R)$ Pure net recharge is the amount of water that has penetrated the surface and reached a static level. It causes contamination vertically, and after reaching a static level, it moves horizontally through the aquifer. To determine the recharge layer, the Piscopo method (Piscopo 2001) is used.

3. The map of the recharge layer was prepared using an overlapping gradient map and soil permeability along with the rainfall score of the region, which in the area under study equals 1 . It is presented in Table 1, according to the meteorological data recorded in the region (Fig. 4). Finally, to obtain the actual rank of recharge, the criteria in Table 2 were used.

4. Aquifer media $(A)$ The length and condition of the route determine the system of groundwater flow in the aquifer

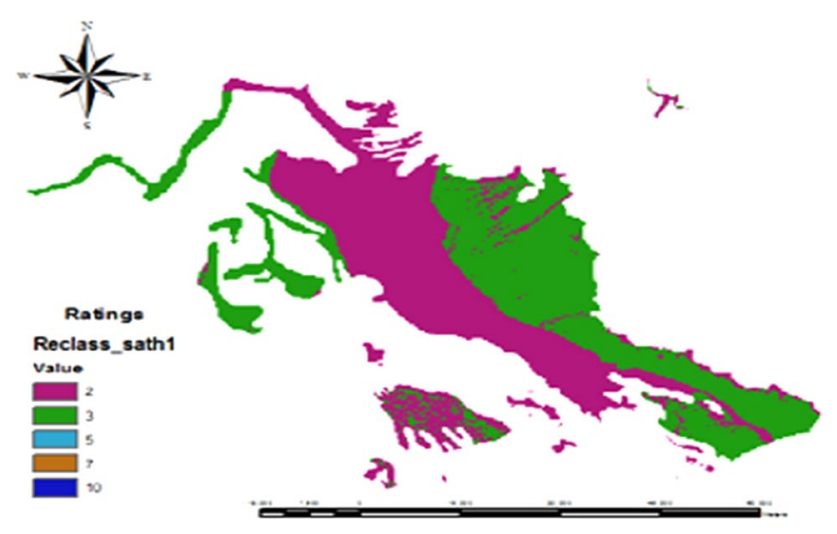

Fig. 3 Depth to water table

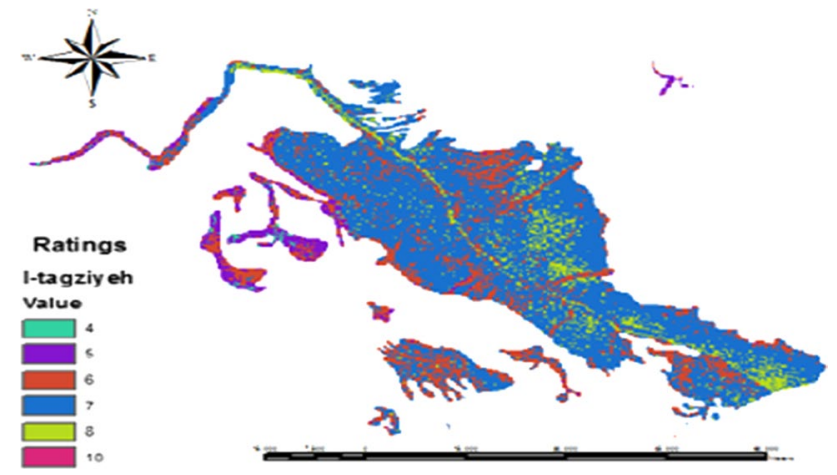

Fig. 4 Net recharge

(Al-Rawabdeh et al. 2013). Condition plays an important role in the rate at which the contamination is spread and the length of the route determines the time required for attenuation processes such as absorption, chemical reactions and distribution of contaminants. To create a layer of the aquifer zone of the piezometer's log were used and so exploratory wells' logs present in the area, logs' geographic location, type and material of the aquifer zone were used (Awawdeh and Jaradat 2010) (Fig. 5). Therefore, in terms of the aquifer material components in each well, each point received ranks according to Table 2.

5. Soil media layer $(S)$ This section is the upper part of the half-saturated region that extends to influence the plant roots or organic creatures' activity. The soil layer has a major impact on the effective recharge to reach a static level. It also affects movement of the contaminant. The layer was developed according to data on resource assessment maps and land capability provided by the Department of Natural Resources and Watershed, Zanjan, and from data of the Soil and Water Research Institute (Fig. 6). Then, the polygons were scored using GIS software as raster in Table 2.

6. Vadose zone (I) The Vadose zone is the upper area of the static level to the surface, and it is composed of unsaturated water. The Vadose zone's thickness and hydraulic properties of geological materials, which control the recharge rate and recharge time of the aquifer, are vital determinants of aquifer vulnerability. In order to provide
Table 1 Data used for measurement of net recharge in the study area

\begin{tabular}{lllllllr}
\hline Slop \% & Rating & Rainfall $(\mathrm{mm})$ & Rating & Soil permeability & Rating & Net recharge & Rating \\
\hline$<2$ & 4 & $>850$ & 4 & High & 5 & $11-13$ & 10 \\
$2-10$ & 3 & $700-850$ & 3 & Moderately high & 4 & $9-11$ & 8 \\
$10-33$ & 2 & $500-700$ & 2 & Moderate & 3 & $7-9$ & 5 \\
$>33$ & 1 & $<500$ & 1 & Slow & 2 & $5-7$ & 3 \\
& & & Very slow & 1 & $3-5$ & 1 \\
\hline
\end{tabular}


Table 2 The ranges and ratings for depth to water, aquifer media, soil media, slope, Vadose zone, an hydraulic conductivity layers

\begin{tabular}{|c|c|c|c|c|c|}
\hline \multicolumn{2}{|c|}{ Depth to water (ft) } & \multicolumn{2}{|l|}{ Aquifer media } & \multicolumn{2}{|l|}{ Soil media } \\
\hline Range & Rating & Range & Rating & Range & Rating \\
\hline $0-5$ & 10 & Shale & 2 & Thin or absent & 10 \\
\hline $5-15$ & 9 & Metamorphic igneous & 3 & Gravel & 10 \\
\hline $15-30$ & 7 & Weathered metamorphic igneous & 4 & Sand & 9 \\
\hline $30-50$ & 5 & Glacial till & 5 & Peat & 8 \\
\hline $50-75$ & 3 & Sandstone/bedded limestone/shale & 6 & Shrinking Clay & 7 \\
\hline $75-100$ & 2 & Thick sandstone & 6 & Sandy loam & 6 \\
\hline \multirow[t]{5}{*}{100} & 1 & Thick limestone & 6 & Loam & 5 \\
\hline & & Sand/gravel & 8 & Silty loam & 4 \\
\hline & & Basalt & 9 & Clay loam & 3 \\
\hline & & Karst limestone & 10 & Muck & 2 \\
\hline & & & & Non-shrinking clay & 1 \\
\hline \multicolumn{2}{|l|}{ Slope \% } & \multicolumn{2}{|l|}{ Vadose zone } & \multicolumn{2}{|c|}{ Hydraulic conductivity $\left(\mathrm{gpd} / \mathrm{ft}^{2}\right)$} \\
\hline Range & Rating & Range & Rating & Range & Rating \\
\hline $0-2$ & 10 & Confining layers & 1 & $1-100$ & 1 \\
\hline $2-6$ & 9 & Silt/clay & 3 & $100-300$ & 2 \\
\hline $6-12$ & 5 & Shale & 3 & $300-700$ & 4 \\
\hline $12-18$ & 3 & Limestone & 6 & $700-1000$ & 6 \\
\hline \multirow[t]{7}{*}{$>18$} & 1 & Sandstone & 6 & $1000-2000$ & 8 \\
\hline & & Sandstone/bedded limestone/shale & 6 & 2000 & 10 \\
\hline & & Sand and gravel with clay/silt & 6 & & \\
\hline & & Metamorphic igneous & 4 & & \\
\hline & & Sand and gravel & 8 & & \\
\hline & & Basalt & 9 & & \\
\hline & & Karst limestone & 10 & & \\
\hline
\end{tabular}

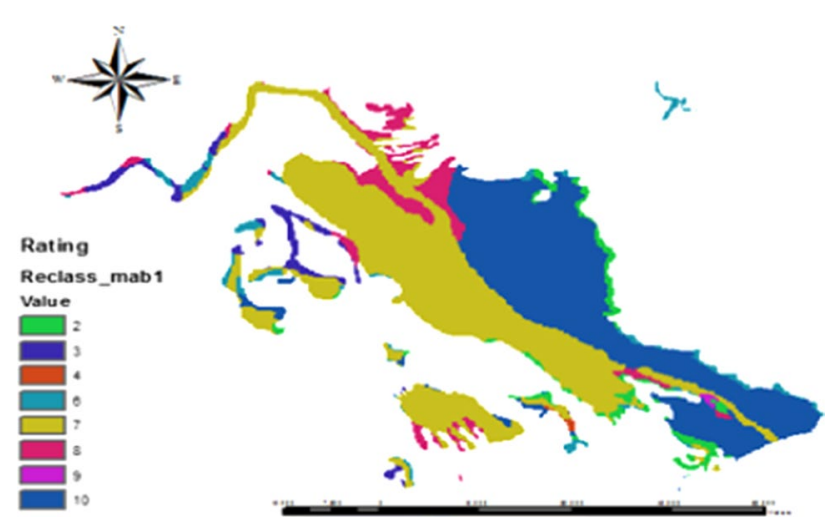

Fig. 5 Aquifer media

the standard in the model, a method similar to the characteristics of the aquifer zone is used. The difference is that in this case, the grading and characteristics of the sediments between the groundwater level and the surface are considered (Fig. 7). Table 2 shows the domain and ranking of the layer.

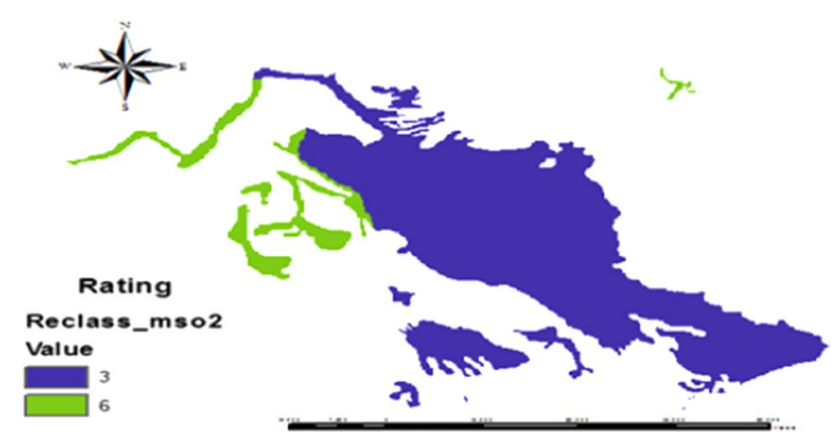

Fig. 6 Soil media

7. Topography $(T)$ It plays an important role in the movement of the contaminant and keeping it on the surface. Additionally, topography is effective in spreading the soil and as a result of attenuation of the contaminations. The layer was prepared according to the topography map of the area (Fig. 8). It was ranked according to Table 2.

8. Hydraulic conductivity $(C)$ This measure controls the movement and spread of the contaminant from the penetration point to the saturated zone. Hydraulic conduc- 


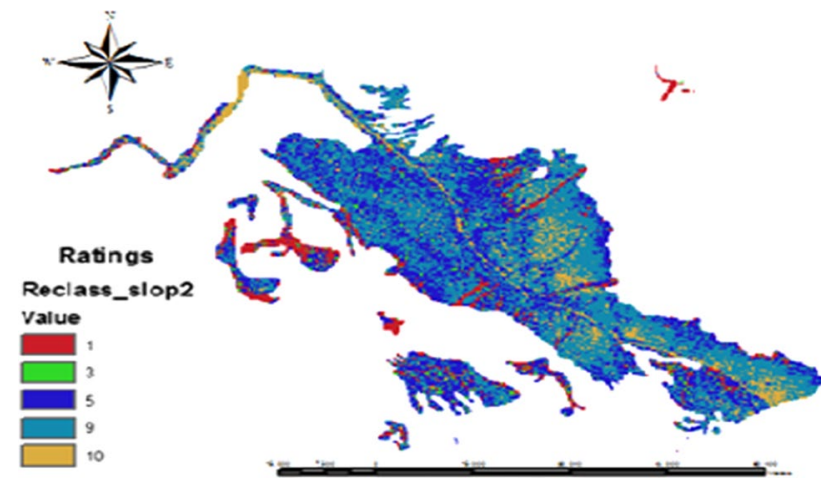

Fig. 7 Impact of Vadose zone

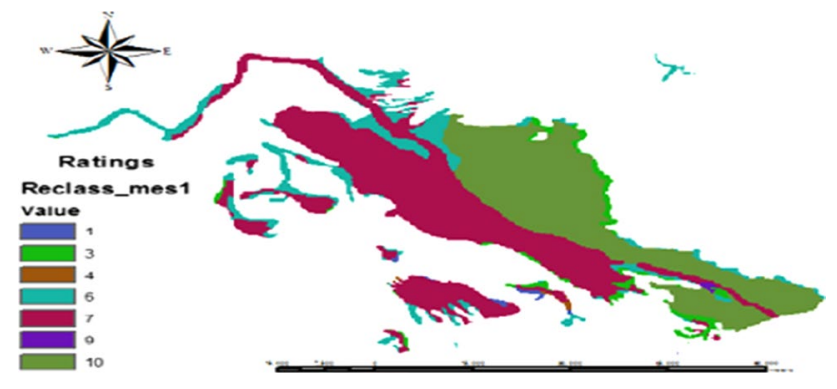

Fig. 8 Topography

tivity data are obtained from pumping test calculations. Given that in test pumps the water transmission capacity coefficient characteristic value is calculated using the saturated thickness of the aquifer, the hydraulic conductivity is obtained by dividing the water transmission capacity coefficient by the saturated thickness of the aquifer. Then, using the raster calculator function, subtracting the map of equivalent thickness alluvium and the map of equivalent depth of water table, the map of saturated thickness is obtained. After dividing the values of the transmission capacity coefficient map by the saturated aquifer's thickness, the plain's hydraulic conductivity map was achieved (Aller et al. 1987) (Fig. 9). The resulting map was prepared according to Table 2. Finally, by combining different layers, the final groundwater vulnerability zoning map was prepared (Fig. 10).

\section{The Concept of Groundwater Vulnerability}

Until now, multiple definitions have been presented with regard to aquifer vulnerability and its concept in hydrogeology, including the definition of "The National Committee of America" in the year 1993. The committee found the reason

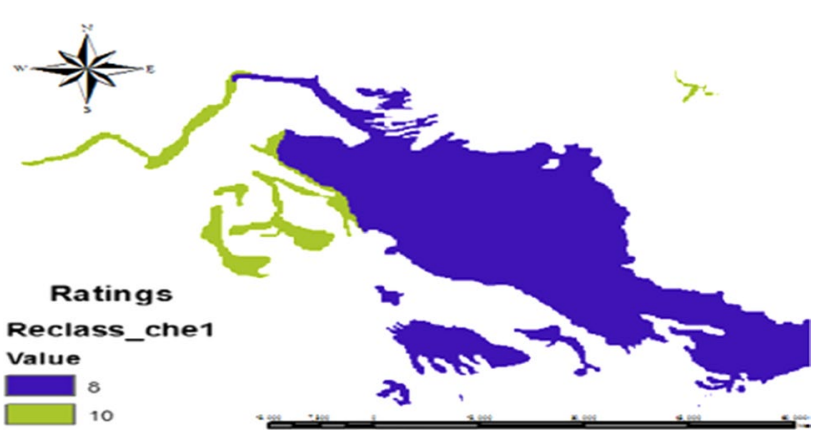

Fig. 9 Hydraulic conductivity

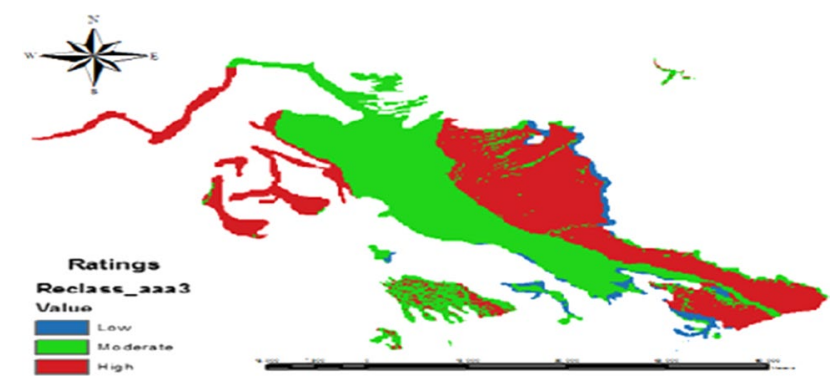

Fig. 10 Groundwater vulnerability to pollution map

for groundwater vulnerability with respect to contamination-it is the tendency or the possibility of contaminants reaching the groundwater after the formation of contaminants in the upper level. The concept of groundwater vulnerability is based on the assumption that the physical environment may protect the groundwater against some adverse natural effects, especially in cases where the contaminant enters underground (El-Naqa et al. 2006). Extraction of groundwater without understanding the environmental impact and the concept of authorized discharge has always been undertaken by mankind. The importance of vulnerability scanning is because groundwater is one of the main sources of drinking water. Another reason for this vulnerability is the high concentration of people (in residential areas, for instance) as well as economic activities in industry and agriculture, which are potential sources of groundwater contamination. This issue has become the focus in growing regions and cities.

\section{DRASTIC Model is Based on Four Assumptions}

1 - Contaminants penetrate the surface of the earth. 2-Contaminants are driven toward the groundwater as a result of rainfall. 3-The mobility of contaminants is the same as water. 4-The area under study is $0.4 \mathrm{~km}$ or more. 
This model consists of seven hydrogeological parameters that contaminate groundwater, including the depth of water, net recharge, aquifer media, soil media, topography, impact of Vadose zone and hydraulic conductivity. The word DRASTIC comes from the first letters of the parameters that assess contamination with this indicator. They include depth of water $(D)$, net recharge $(R)$, aquifer media $(A)$, soil media $(S)$, topography $(T)$, impact of Vadose zone $(I)$ and hydraulic conductivity $(C)$. The purpose of this study is using the DRASTIC model to assess groundwater vulnerability of the area under study.

Considering the map of aquifer vulnerability and with regard to the potential aquifer contamination at various areas, it is possible to determine a suitable site for the landfill. At present, about $49.03 \%$ of the aquifers are in average vulnerability situation; by considering them, a suitable site for the landfill can be determined.

\section{Preparation of Layer for ArcGis Environment}

In this study then, 11 factors affecting the location of a municipal waste landfill have been employed, which include underground water depth, distance from urban areas, distance from rural areas, distance from the main road, distance from rivers, distance from wells and aqueducts, soil texture, geology, land use, slope percentage and rainfall. Generally, in this paper, the inappropriate locations were first identified using GIS software and detected to limit the study area. Then, taking into account the criteria of technical, economic, political and social, as well as the views of experts and relevant laws and the use of the AHP method, paired comparisons were conducted.

Finally, weights were assigned to 11 considered layers. By summing the weights obtained for maps, the map of the appropriate location chosen to bury the waste was determined. Finally, this map was classified into three classes of high, intermediate and low. Given that an area of 36 hectares was required, a limited number of places obtained remained. Using the PRPMOTHEE method (multi-criteria decision making) among these high and intermediate classes, these locations were ranked and the most appropriate location was chosen among the other options.

\section{Standardization of Criteria Maps}

For locating, the effective layers in the locating procedure were first standardized. For this purpose, the analytic hierarchy process (AHP) has been used. In this study, by presenting the priority of options in the partial goals of decision- making to locate municipal solid waste landfill and advancing the problem in parallel, separately from each other, a way was presented so that decision-makers could choose the best option in tangible conditions.

\subsection{Standardization of Maps Based on Analytic Hierarchy Process (AHP)}

The AHP method was proposed in the 1980 s by Saaty. This is one of the most used multi-attribute decision-making methods. This allows the problem hierarchically to set the priorities, based on objective. Therefore, this method is mainly used to determine the priority of options in a general goal. In fact, this model is designed to solve multi-criteria problems.

To prioritize criteria, first desired criteria through interviews and completing a questionnaire with 15 experts from Environment Organization and regional water companies whose job is to monitor the quality of surface and groundwater resources to determine environmental criteria and Municipal Organization in the field of criteria, this criteria were determined. By the opinion of economic experts, sociocultural and economic criteria were also examined and determined.

This approach makes various options involved in decision making, and it has the ability to use sensitivity analysis on the criteria and subcriteria. In addition, the basis of pairwise comparison is made that makes the analysis and calculations easy. In addition, it shows the compatibility and incompatibility of decision, which is the major advantage of this approach in multi-criteria decision making. In pairwise comparison matrices, ith row is compared with jth column (Saaty 1980).

The eigenvalue method is a commonly used method to obtain the weight of parameters of a pairwise comparison matrix, where the eigenvalue of a pairwise comparison matrix is obtained from Eq. (1) (Saaty 1980). The main steps of this method include the development of a comparison matrix at each hierarchical level of comparison of the weights for each component of the hierarchy and estimation of compliance rate of decision making:

$A-\lambda I=0$

In this relationship, $A$ is a comparison matrix, $\lambda$ is the eigenvalue of matrix $A$ and $I$ is the identity matrix. The final weights can be calculated from Eq. 2:

$D \cdot W=\lambda_{\max } \cdot W$

$C \cdot I=\lambda_{\max }-n / n-1$

where $n$ is the number of criteria with dimensions of matrix $A$ and max $\lambda$ is the greatest eigenvalue of matrix $A$. Then, the compliance rate is determined as follows: 


$$
\mathrm{CR}=\mathrm{CI} / \mathrm{RI}
$$

If $\mathrm{CR}<0.1$, in this case, there is compatibility between the pairwise comparisons, otherwise the decision-maker should review pairwise comparisons (Ying et al. 2007).

RI's have also been prepared by Saaty and Vargas (Saaty and Vargas 1991) for matrices in different dimensions. These numbers are listed in Table 3 (Saaty and Vargas 1991).

\section{Results and Discussion}

After ranking each of the parameters required for assessing groundwater vulnerability, an attempt was made to prepare the map of vulnerability in the GIS software. As we know, through combination and incorporation of the seven-parameter layers, the vulnerability map is prepared.

In GIS software, for combining raster layers, the overlay function is used. The following points should be considered in incorporating layers: (1) all the layers created should be rasterized; (2) all the pixels should be of same size in all the layers; and (3) all the layers are produced in the same coordinates system. Since the data used had been in raster format, an overlay function was used in this study.

The function, both mathematically and weighted, combines the data (Table 4). Given these layers, in the DRASTIC model, each parameter had a specific weight to combine and incorporate the data for which the weighted overlay function through the raster calculator menu in ArcGIS software was used. To do this, all the layers with coefficients were defined for the model and then incorporation of layers was performed (Table 5).

After preparing all seven layers of the DRASTIC model parameters in GIS, to incorporate the maps, the command "raster calculator" in "spatial analyst" toolbox was used. Using the raster calculator, each layer was multiplied by its coefficient and then all the layers were totaled. Finally, the vulnerable zones were classified based on this method (Table 6).

\subsection{Site Selection}

Before performing the overlap operations, the waste landfill limiters in Zanjan were examined. These limiters were used

Table 3 Indicator of random discord
Table 4 DRASTIC parameter assigned weights

\begin{tabular}{lll}
\hline Parameter & Unit & Weight \\
\hline Depth to water table & M & 5 \\
Net recharge & mm/year & 4 \\
Aquifer media & - & 3 \\
Soil media & - & 2 \\
Topography & $\%$ & 1 \\
Impact of vadose zone & - & 5 \\
Hydraulic conductivity & m/day & \\
\hline
\end{tabular}

due to the study of research literature, especially the environmental criteria of Environmental Protection Organization, 2009 (Table 7). Applying restrictive criteria due to the rules of Environmental Protection Agency of Iran, unsuitable lands were removed, Suitable options for landfilling in three environmental, social, and economic purposes were weighted by the AHP method. Weighing the criteria in the form of pairwise comparisons was done by completing a questionnaire by 15 experts, including the environment, governorate, natural resources and Zanjan municipality. Finally, these areas were prioritized.

Table 8 shows the matrix prepared for the relative importance of the 11 parameters; these parameters are compared pairwise. Considering the importance of determining the location of municipal waste landfill, values of 1 (equal importance) up to 9 (extremely important) are allocated to themselves in the matrix. On the contrary, if it is less important, it will be expressed as a fraction of 1 on 1-9 (Table 8).

Since the CR index value equal to 0.066 for the matrix with increasing power of 5 is less than $10 \%$, it indicates a high compatibility with this matrix and this value is used to obtain the appropriation index. To identify areas with an acceptable potential for municipal waste landfill in the city of Zanjan, 11 prepared digital layers including depth to groundwater (Fig. 11), distance of wells and Qantas (Fig. 12), distance of river (Fig. 13), distance of city (Fig. 14), distance of villages (Fig. 15), distance of roads (Fig. 16, land use (Fig. 17), rain (Fig. 18), soil (Fig. 19), geology (Fig. 20), slope (Fig. 21), distance of river (Fig. 22) were combined together.

The final layer is obtained by superposition of these layers. By the effect of the provisions and analysis of overlap,

Table 5 DRASTIC index and vulnerability class

\begin{tabular}{ll}
\hline DRASTIC index & Vulnerability class \\
\hline $1-100$ & Low \\
$101-140$ & Moderate \\
$141-200$ & High \\
$>200$ & Very high
\end{tabular}


Table 6 Ranges and rating for various hydrogeological setting using DRASTIC data for the study area

\begin{tabular}{|c|c|c|c|c|c|c|c|}
\hline \multicolumn{4}{|c|}{ Depth to groundwater } & \multicolumn{4}{|c|}{ Net recharge } \\
\hline Ranges (m) Dr & Ratings & \multicolumn{2}{|c|}{ Subindex (Dr*Dw) } & \multicolumn{2}{|c|}{ Ranges (mm) Rw } & Ratings ( $\mathrm{Rr} * \mathrm{Rw})$ & Subindex \\
\hline $0-20$ & 10 & \multicolumn{2}{|l|}{50} & \multicolumn{2}{|l|}{$11-13$} & 10 & 40 \\
\hline $25-30$ & 7 & \multicolumn{2}{|l|}{35} & \multicolumn{2}{|l|}{$9-11$} & 8 & 32 \\
\hline $30-35$ & 5 & \multicolumn{2}{|l|}{25} & \multicolumn{2}{|l|}{$7-9$} & 5 & 20 \\
\hline $35-40$ & 3 & \multicolumn{2}{|l|}{15} & \multicolumn{2}{|l|}{$5-7$} & 3 & 12 \\
\hline $40-45$ & 2 & \multicolumn{2}{|l|}{10} & \multicolumn{2}{|l|}{$3-5$} & 1 & 4 \\
\hline Weight (Dw) & \multicolumn{3}{|l|}{5} & \multicolumn{2}{|c|}{ Weight (Rw) } & 4 & \\
\hline \multicolumn{4}{|l|}{ Aquifer media } & & \multicolumn{3}{|l|}{ Soil media } \\
\hline \multicolumn{2}{|l|}{ Type } & Ratings Ar & \multicolumn{2}{|c|}{ Subindex (Ar*Aw) } & Type & Ratings Sr & $\begin{array}{l}\text { Sub- } \\
\text { index } \\
\text { Sr*Sw }\end{array}$ \\
\hline \multicolumn{2}{|l|}{ Karst limestone } & 10 & \multicolumn{2}{|l|}{30} & Sandy loam & 6 & 12 \\
\hline \multicolumn{2}{|l|}{ Basalt } & 9 & \multicolumn{2}{|l|}{27} & Loam & 5 & 10 \\
\hline \multicolumn{2}{|l|}{ Sand/gravel } & 8 & 24 & & clay loam & 3 & 6 \\
\hline $\begin{array}{l}\text { Bedded sandston } \\
\text { Limestone and sh }\end{array}$ & ences & 6 & 18 & & & & \\
\hline Weathered metan & gneous & 4 & 12 & & & & \\
\hline Metamorphic ign & & 3 & 9 & & & & \\
\hline Shale & & 2 & 6 & & & & \\
\hline Weight (Aw) & & 3 & & & Weight (Sw) & 2 & \\
\hline Topography & & & & Impact of vac & lose zone & & \\
\hline Ranges (\%) & Ratings & Subindex & & Ranges (mm) & & Ratings & Subindex \\
\hline $0-2$ & 10 & 10 & & Karst limesto & & 10 & 50 \\
\hline $2-6$ & 9 & 9 & & Basalt & & 9 & 45 \\
\hline $6-12$ & 5 & 5 & & Sand/gravel & & 6 & 30 \\
\hline $12-18$ & 3 & 3 & & Limestone & & 6 & 30 \\
\hline $18<$ & 1 & 1 & & Metamorphic & igneous & 4 & 20 \\
\hline Weight (Tw) & 1 & & & Shale & & 3 & 15 \\
\hline & & & & Weight (Iw) & & 5 & \\
\hline Hydraulic conduc & & & & & & & \\
\hline $\begin{array}{l}\text { Ranges }(\mathrm{m} / \mathrm{d}) \\
\mathrm{Cr}\end{array}$ & & & & ings & & & $\begin{array}{l}\text { Subindex } \\
\left(\mathrm{Cr}{ }^{*} \mathrm{Cw}\right)\end{array}$ \\
\hline $40-80$ & & & 8 & & & & 24 \\
\hline $80<$ & & & 10 & & & & 30 \\
\hline Weight (Cw) & & & 3 & & & & \\
\hline
\end{tabular}

a raster layer is obtained. This layer based on points is classified into five classes: N2 zero points, N1 points $1, \mathrm{~S} 3$ points 2 , S2 points 3 , and $\mathrm{S} 1$ points 4 . After obtaining the final map shown in Fig. 23, field visits were conducted and relevant expert opinions were reviewed on the areas where restrictions for the construction of the landfill were removed. Finally, with regard to the conditions, the area needed for the landfill over the next 20 years is estimated at about 36 hectares. Figure 24 is approved as a final locating map.

In this research, AHP and DRASTIC methods were separately used to determine the differences between two models to evaluate the appropriate location for landfilling. The results showed that the target locations were in the medium range due to DRASTIC method and in the excellent range due to AHP method. Comparing the models shows a slight difference due to the difference in the parameters considered for each model.

\subsection{PROMETHEE Method}

Among the various methods that have been presented in the form of outranking methods, the PROMETHEE 
Table 7 Environmental criteria of the Environmental Protection Organization

\begin{tabular}{ll}
\hline Criteria & Terms \\
\hline Groundwater depth (m) & $20<$ \\
Distance to wells and aqueducts (m) & $4000<$ \\
Distance from surface water_rivers (m) & $2000<$ \\
Distance from urban areas (m) & $8500<$ \\
Distance from rural areas (m) & $500-1000$ \\
Distance from main roads (m) & $500-1000$ \\
Land use & without any covers \\
Slope \% & $<2$ \\
Geology & Shale, marl, clay \\
\hline
\end{tabular}

method has found many applications in recent years. This method, as a decision-making support and confusing method, without the need for too much information, creates stable and understandable results.

Various models of this method have been presented for investigating decision-making issues such that PROMETHEE I (for partial ranking of options), PROMETHEE II (for complete ranking of options), PROMETHEE III (for ranking based on interval), PROMETHEE IV (for contiguous states), PROMETHEE V (to solve decision-making problems with restrictions) and PROMETHEE VI (with development of sensitivity analysis tools) can be noted.

The most important strengths of this method compared to other methods of decision making are ease of use for users, enabling the interpretation of the parameters (classification of indices and options), stability of results compared with most other methods, allowing for quick and simple sensitivity analysis, the ability of the graphic design of modeling and taking into account the various constraints in the optimization of the decision.

In fact, this model is designed to solve multi-criteria problems. The main feature of PROMETHEE is that the data required for this method are quite clear and understandable for analysts and decision-makers and are in fact, one of the most understandable multi-criteria methods.

\subsubsection{For Promethean Method, They Are Divided into Two Categories}

7.2.1.1 Weight or Data Among Criteria Data among criteria are actually weights which show the relative importance of different criteria. In the perimeter method, the model assumes that the decision-maker can determine the weights. Weights are nonnegative numbers which are independent of measurement unit.

Since weights can be normally entered, we will have:

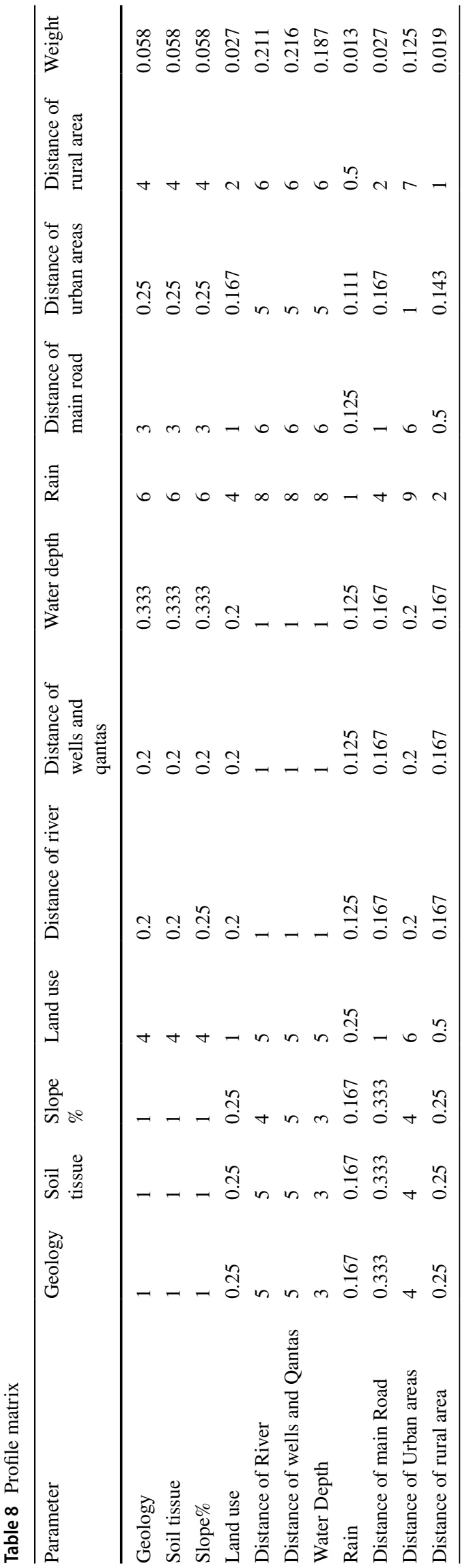




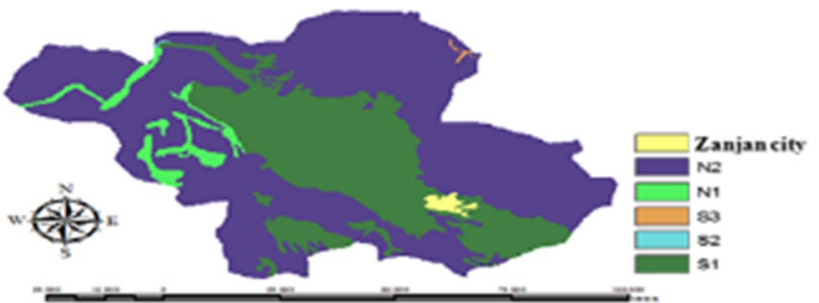

Fig. 11 Depth to groundwater map

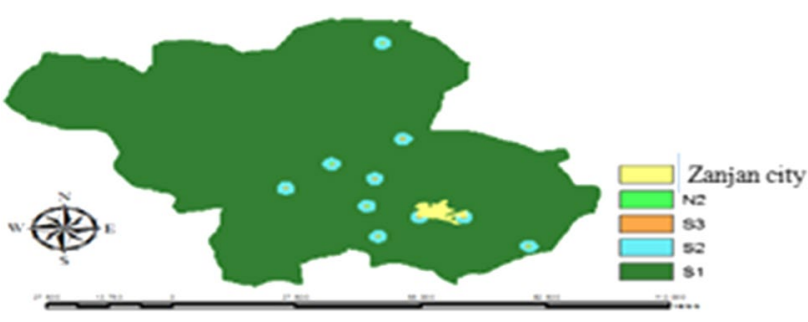

Fig. 12 Distance of wells and Qantas map

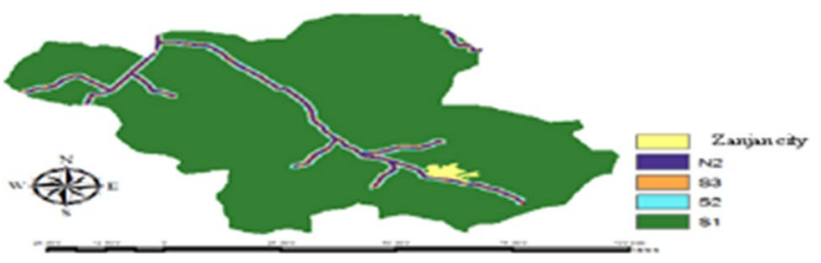

Fig. 13 Distance of river

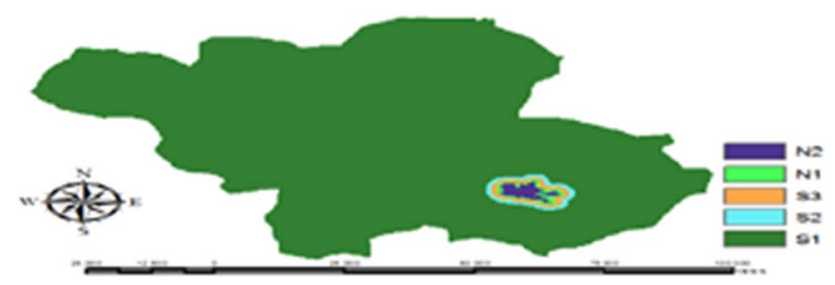

Fig. 14 Distance of city

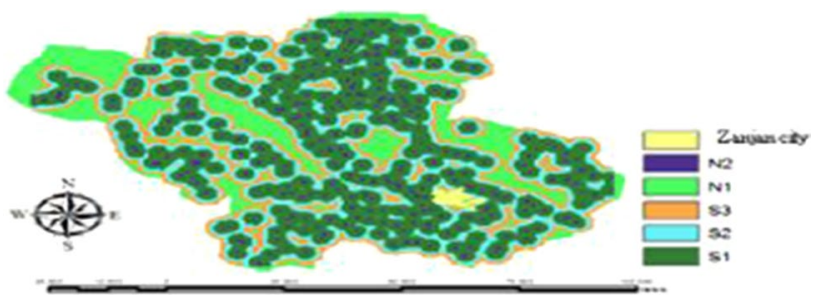

Fig. 15 Distance of villages map

seces iㅡ. Springer

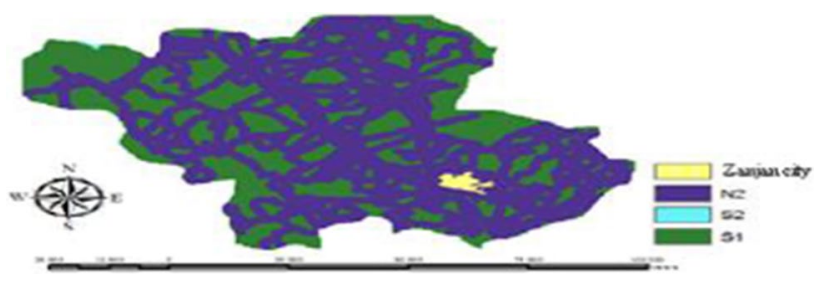

Fig. 16 Distance of roads map

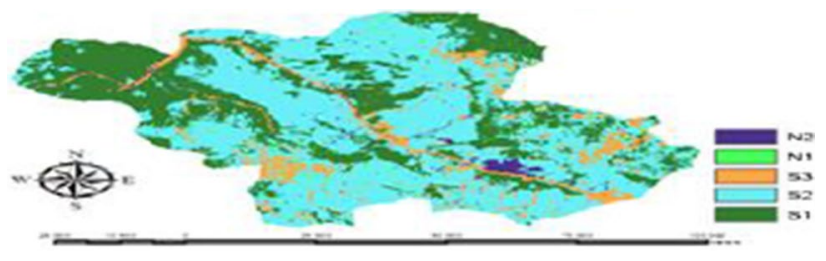

Fig. 17 Land use map

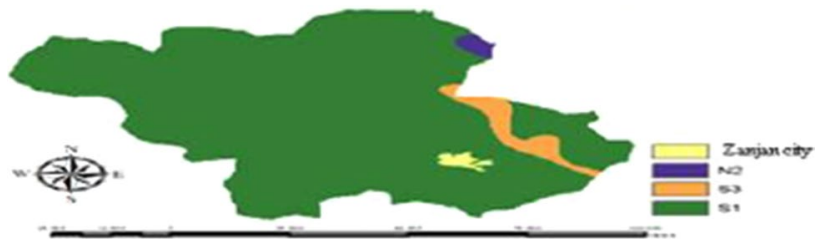

Fig. 18 Rain map

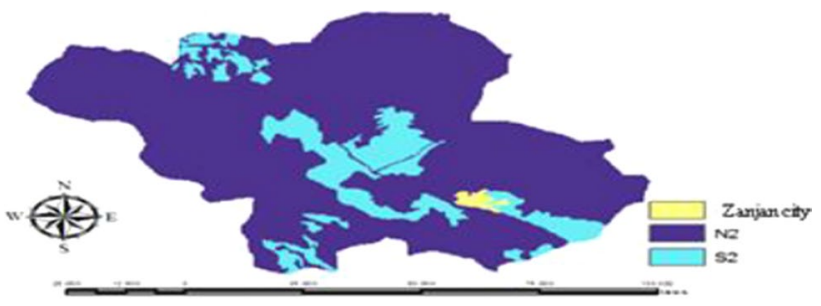

Fig. 19 Soil map

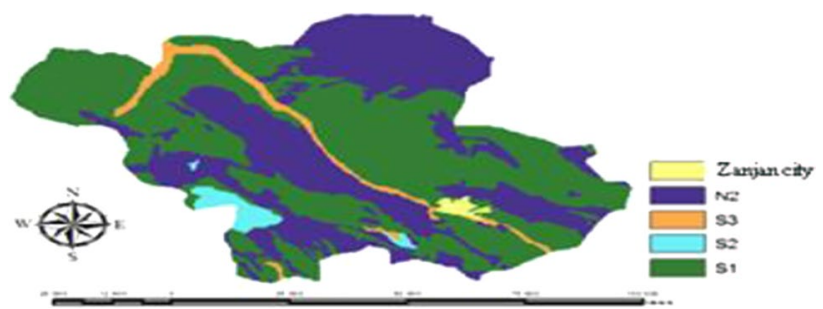

Fig. 20 Geology map 


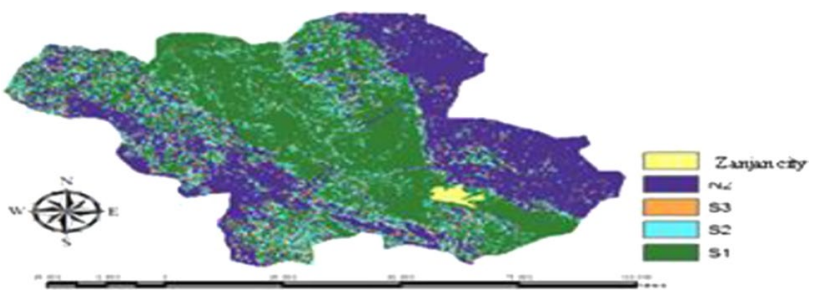

Fig. 21 Slope map

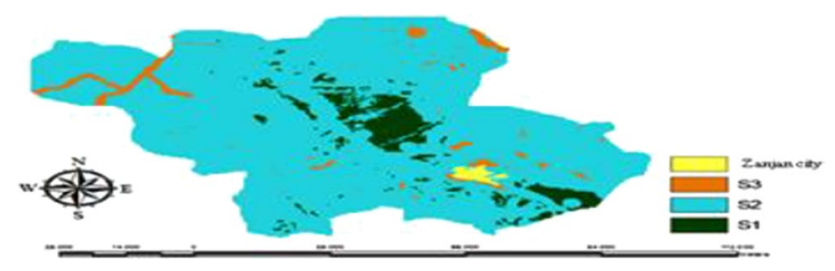

Fig. 22 Distance of river map

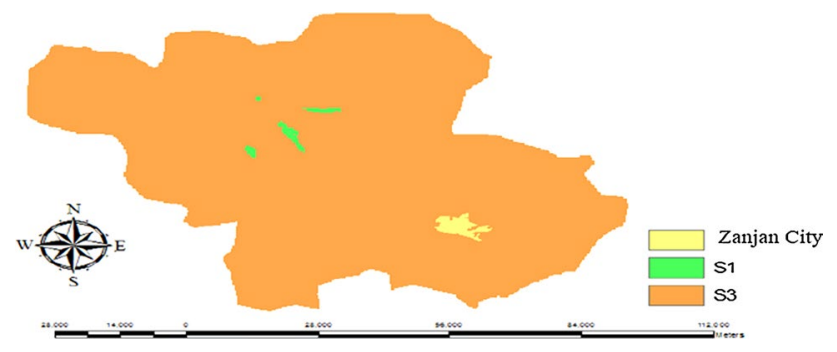

Fig. 23 Initial map location AHP method

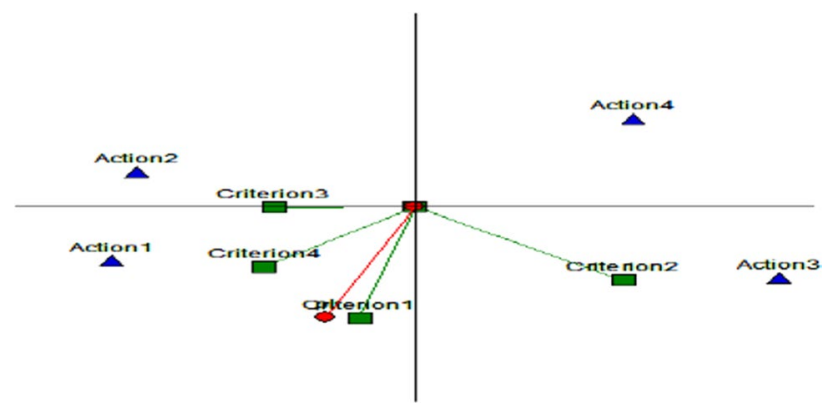

Fig. 24 Final map location hierarchical analysis method

$$
\sum_{i=1}^{K} W_{j}=1
$$

where $W$ is the weight of criteria, and $k$ is the number of criteria.

In this method, weighing criterion is not simple which depends on decision-maker's knowledge and experience. The weights of the AHP method were used to weight specified criteria.

Preference function or information within each criterion:

The Preference function converts the difference between two criteria for a given criterion to a degree of preference which varies from 0 to 1 .

For each criterion, decision-makers should choose a preference function. Numerous preference functions can be defined. These six preferred functions are used, namely linear function, Gaussian function, ordinary function, flat function, V-shaped function and U-shaped function (Table 9).

\subsection{Ranking with PROMETHEE Method}

The ranking of the options in this method is conducted by pairwise comparison of options in each indicator. The comparison is measured based on a predefined superiority function with amplitude [0, 1$]$.

The steps of the PROMETHEE method include (Brans 1982):

The first step The differences in sizes:

$\operatorname{dj}(a, b)=\mathrm{fj}(a)-\mathrm{fj}(b)$

The second step Calculating the priority function of $\mathrm{pj}(a$, $b$ ) with respect to the above-mentioned functions, $p$ of each option is calculated with respect to the other options.

After ranking and calculating the net flow, ranking will be obtained based on the net flow. Some preferred functions have been presented to define the priority function of the options such as linear, Gaussian, V-shaped and U-shaped functions (Brans and Mareschal 1995). In this paper, the preferred V-shaped functions with the specifications of Table 9 have been used. To rank the areas in the high class, the PROMETHEE II method has been used according to Fig. 23.

Therefore, first, the indicator type, type of priority function, indifference and priority thresholds for each index were determined as described in Table 10. Among the 11 criteria, four criteria affecting underground water depth, distance from the river, distance from the main roads and the city limits have been considered.

The third step The priority of each option compared to other options: Rhythmic priority of option as compared to option $\mathrm{b}$ is as follows:

$$
\begin{aligned}
& \pi(a, b) \Rightarrow \pi(a, b)=\sum \mathrm{pj}(a, b) \mathrm{wj} \\
& \pi(b, a) \Rightarrow \pi(b, a)=\sum \mathrm{pj}(b, a) \mathrm{wj}
\end{aligned}
$$


Table 9 Preference function

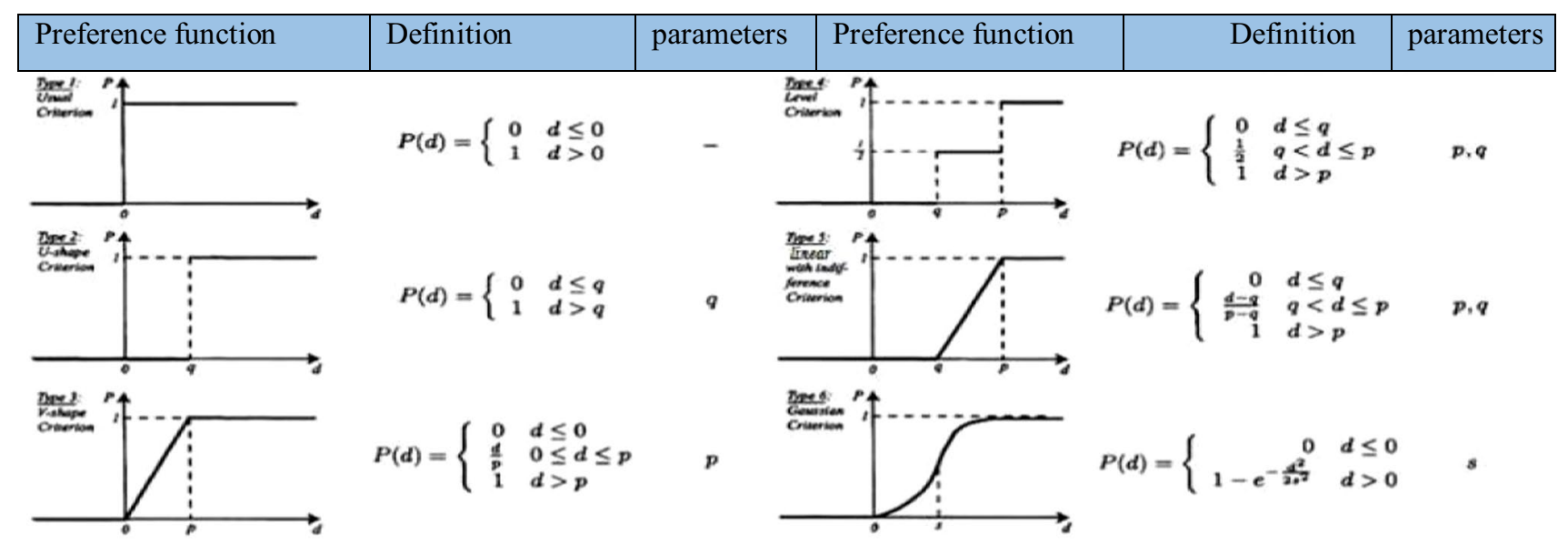

Table 10 Preference function

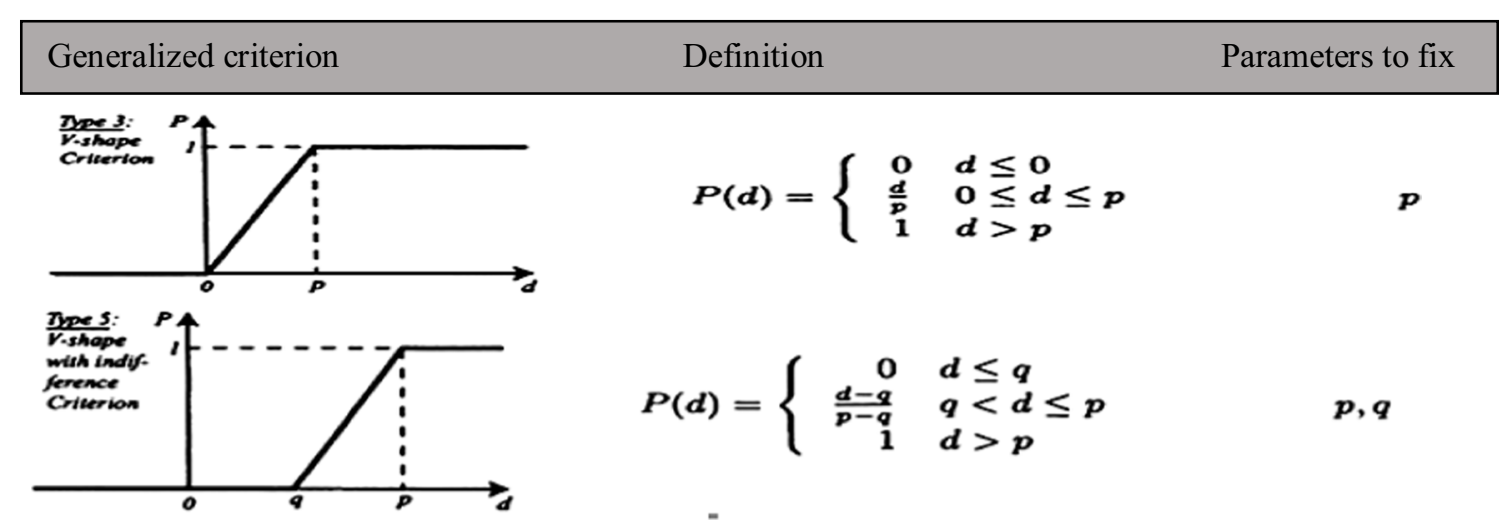

Calculating the input and output flow of data:

Calculation of the output flow:

$\Phi^{+}(a)=[1 /(n-1)] \sum \pi(a, x)$

Calculation of the input flow:

$\Phi^{-}(a)=[1 / n-1] \sum \pi(x, a)$

The fourth step Calculating the positive and negative flow and net flow:

$\Phi=\Phi^{+}-\Phi^{-}$

After ranking and calculating the net flow, ranking will be obtained based on the net flow. Some preferred functions have been presented to define the priority function of the options such as linear, Gaussian, V-shaped and U-shaped functions (Brans and Mareschal 1995). In this paper, the preferred V-shaped functions with the specifications of Table 10 have been used. To rank the areas in the high class, the PROMETHEE II method has been used according to Fig. 23. Therefore, first, the indicator type, type of priority function, indifference and priority thresholds for each index were determined as described in Table 10. In addition, among the 11 criteria, 4 criteria affecting underground water depth, distance from the river, distance from the main roads and the city limits are considered in Table 11.

\subsection{Geometrical Analysis for Interactive Assistance and Estimation of Sensitivity Analysis}

The GAIA method has been used for increasing the efficiency of the PROMETHEE methods, and graphics and anatomical capabilities were added to it. This is because, in the multi-criteria problems, it is very important to have the decision-maker about the incompatibility of indices and index weights on the final results. In fact, the GAIA method reflects a two-dimensional view of the preferences of the decision-maker (Mareschal and Bran's 1988).

As illustrated in Fig. 25, the red axis was the decision axis and, therefore, the first option was closer to the decision-making criteria and net flow compared to the other 
Table 11 Type of indicator, type of priority function, indifference and priority threshold and priority with PROMETHEE II method

\begin{tabular}{lllll}
\hline & $\begin{array}{l}\text { Createrion1 } \\
(\mathrm{m})\end{array}$ & $\begin{array}{l}\text { Createrion2 } \\
(\mathrm{m})\end{array}$ & $\begin{array}{l}\text { Createrion3 } \\
\text { Distance of urban area }\end{array}$ & $\begin{array}{l}\text { Createrion4 } \\
\text { Distance of road }\end{array}$ \\
\hline Max/Min & Max & Max & Min & Min \\
Weight & 0.20 & 0.23 & 0.29 & 0.28 \\
Preference function & v-shaped & v-shaped & v-shaped with indiffer- & v-shaped \\
& criteria & criteria & ence threshold & linear \\
& & & criteria & \\
Indifference & - & - & 1 & - \\
threshold & & & 3 & 2 \\
Preference threshold & 4 & 1 & 1.0 & 4.0 \\
Action 1 & 10.0 & 6.0 & 2.0 & 5.0 \\
Action 2 & 10.0 & 4.0 & 4.0 & 6.0 \\
Action 3 & 10.0 & 9.0 & 3.0 & 6.0 \\
Action 4 & 7.0 & 8.0 & &
\end{tabular}

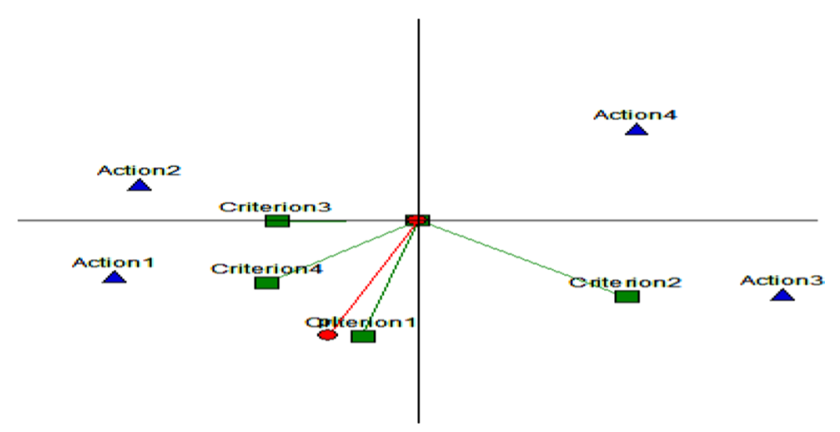

Fig. 25 GAIA method

Table 12 Calculation of net flows

\begin{tabular}{lllr}
\hline & $\Phi^{+}(a)$ & $\Phi^{-}(a)$ & \multicolumn{1}{c}{$\Phi(a)$} \\
\hline Action 1 & 0.5518 & 0.1556 & 0.3963 \\
Action 2 & 0.2389 & 0.3117 & -0.0729 \\
Action 3 & 0.2834 & 0.3314 & -0.0481 \\
Action 4 & 0.1877 & 0.4630 & -0.2753 \\
\hline
\end{tabular}

options, and so it is the first priority. It is also discernible from Table 12 that the reason is that the net flow was higher in the first option and will be the first priority to bury the wastes of the city of Zanjan.

\subsection{Sensitivity Analysis is Performed for Two Reasons}

The first reason is the MCDM method has a certain level of uncertainty in different parameters of the model. The next reason is that the sensitivity analysis provides a further investigation of data and model. Hence, the decision-maker may be skeptical about the weight of a criterion through which it can view and examine the result by changing the weight as in Table 13 and add or remove a criterion.

Therefore, after determining the rank for each criterion, by sensitivity analysis it is possible to determine the strength of the proposed options. Sensitivity analysis deals with the changes in output compared to input change. If the changes do not significantly affect the output, then the ranking has enough strength.

A range known as the stable range is defined for each criterion in the PROMETHEE method. If the standard weight is defined in this range, the final ranking will not change in the PROMETHEE II method. Therefore, this tool is very useful for a sensitivity analysis. Considering the range provided for weights of criteria in Table 13, it indicates the appropriate selected option, which has the strength required.

\subsection{Location}

In this study, 11 operating criteria for the location of municipal waste landfill in Zanjan were used. These are as follows: depth of water, soil media, geology, distance from the city, and distance from the countryside, distance from wells and aqueducts, topography, land use, distance from rivers, rainfall, and distance from main roads. All the maps except that of the wells and aqueducts were obtained from the Bureau of Agricultural Research Center of Zanjan province, and the map of wells and aqueducts was obtained from the Zanjan Regional Water Authority.

Then, the layers were standardized on the basis of environmental legislations and regional conditions, and each criterion was assigned a weight using the analytic hierarchy process. In order to resolve the conflicts arising from differences of opinions by decision-makers about the inconsistency rate (CR), it was taken to be less than $10 \%(0.66)$. Finally, the initial map of a suitable location for municipal 
Table 13 Analysis of the sensitivity in the weight of the criteria

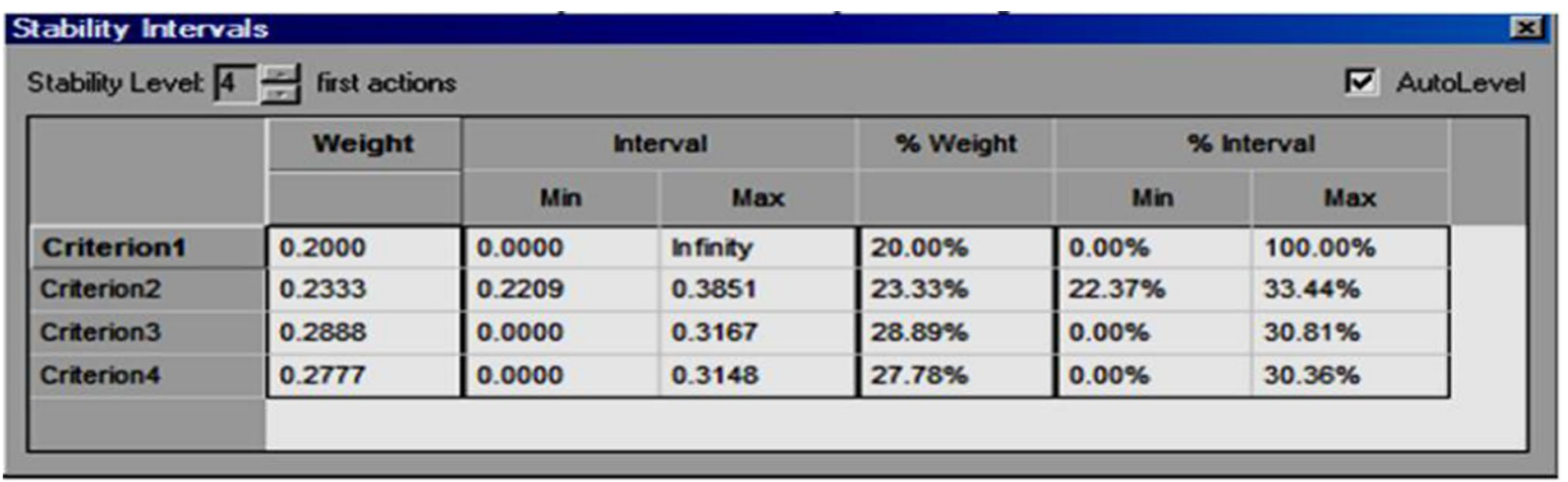

waste disposal was specified. It was divided into three classes of high, medium and low.

Throughout, the map showed that these areas are mainly present in the northern and central parts of the area under study. Owing to suitable distance from residential areas, quick access to roads, sufficient distance from surface waters and rivers, suitable topography, high depth of water, and due to the soil in the area, these areas are relatively deep; therefore, in this study, these areas are presented as most suitable for the location of landfills in Fig. 10.

The PROMETHEE method works as a multi-decision method. Combining this method with GAIA methods provides a useful tool for determining the relationship between criteria and decision-makers. Since using AHP and DRASTIC methods, the desired locations were in appropriate range. Therefore, the PROMETHEE method was used to determine the best option among other suitable options which have the necessary conditions in terms of effective standards to determine the burial site.

\subsection{Limitations of the Study}

By strictly implementing the existing laws and restrictions in locating and reviewing the environmental regulations for landfilling (Table 14), the appropriate location was selected with more attention to soil type and physical properties of soil, vegetation, groundwater and other conditions of region.

On the other hand, due to the large volume of pollution caused by landfilling of municipal waste, the relevant authorities should demand the effective expansion and infiltration of pollution caused by pollution into the environment and natural resources, and finally, groundwater.

In this study, by obtaining the different areas of Zanjan Plain in terms of pollution potential, to continue working in this field, the amount of pollution in each area should be determined (Table 15). Then, the amount of pollution should be compared to its standard values in terms of drinking and agriculture.
Table 14 Landfill restrictions in the study area

\begin{tabular}{ll}
\hline Limitations & Threshold \\
\hline Water depth (m) & $<5$ \\
Distance of wells and Qantas (m) & $<350$ \\
Distance from surface water (m) & $<300$ \\
Distance from urban areas (m) & $<500$ \\
Distance from villages (m) & $<500$ \\
Distance from main roads (km) & $<1000$ \\
Land use & Jungle/river bed/ \\
& residential areas \\
Slope \% & $20<$ \\
Geology & Sandstone/dolomite \\
\hline
\end{tabular}

The general steps of the usual procedural to be applied in this research are shown in Fig. 26.

\section{Discussion}

In order to create a clean and healthy environment for the citizens, a comprehensive management of solid waste collection and disposal is required. The basis of health and hygiene of the cities is their cleanliness; collection and disposal are presented as the most important and influential factors which require addressing the issue of a need for a proper system of waste management.

A proper waste management cycle includes elements required to reduce production, collection, transportation, processing, recycling and disposal from the production point to the landfill; the implementation of each of the above steps requires careful planning and design. One of the things that must be considered in the design of environmental landfill site is the issue of leachate management and preventing the contamination of groundwater.

In this study, given that the DRASTIC method is more practical compared to other methods of determining 
Table 15 Characteristics of selected areas in the study area

\begin{tabular}{|c|c|c|c|c|}
\hline & Area 1 & Area 2 & Area 3 & Area 4 \\
\hline Water depth (m) & 53 & 45 & 26 & 22 \\
\hline $\begin{array}{l}\text { Distance of wells and Qantas } \\
\text { (m) }\end{array}$ & 4800 & 4000 & 3500 & 2900 \\
\hline $\begin{array}{l}\text { Distance from surface water } \\
\text { (m) }\end{array}$ & $2000<$ & $2000<$ & $2000<$ & $2000<$ \\
\hline $\begin{array}{l}\text { Distance from urban areas } \\
(\mathrm{km})\end{array}$ & 10 & 6 & 7 & 4 \\
\hline Distance from villages (m) & $1500<$ & $1500<$ & $1500<$ & $1500<$ \\
\hline $\begin{array}{l}\text { Distance from main roads } \\
(\mathrm{km})\end{array}$ & 4 & 7 & 6 & 9 \\
\hline Land use & Low-density pasture/rained & Semi-dense pasture/rained & Semi-dense pasture/rained & Semi-dense pasture/rained \\
\hline Slope & 5 & 7 & 10 & 14 \\
\hline Geology & Shale/marl/clay & Marl/loess thin & Silty/loess thin & Calcareous marl \\
\hline
\end{tabular}

potential aquifer vulnerability, and, in the provision, more parameters are used, this method is used to assess the potential aquifer contamination to leachate from the waste. Zoning map of the aquifer vulnerability of the study area, which is obtained from incorporating the seven-parameter raster maps of DRASTIC model with respect to the weight of each parameter in GIS, shows that the parameters of depth to water $(D)$ and net recharge $(R)$ have the most influence on determining the aquifer vulnerability.

In the map, it is found that $53 \%$ of the study area has a low and medium vulnerability and about $47 \%$ has a high vulnerability. The results show that the DRASTIC index values for the study area ranged from 82 to 186 and were divided into low-, medium- and high-vulnerability classes. GIS was found to provide an efficient environment for such analyses as shown in Table 16.

In this study, the inappropriate places were first determined and removed by the GIS so that there are a limited number of studied areas. Then, taking into account economic, social, cultural and political criteria and using the AHP method, pairwise comparisons have been conducted and weights were assigned to the considered layer. Finally, the right location maps for municipal waste disposal were identified with an area of at least 36 hectares, with 270 tons per day for the next 20 years.

These were classified into high, intermediate and low classes. Then, among the high class places, according to geological formations such as the absence of seams and cracks in the bedrock and features of the soil and groundwater situation, and considering factors such as lack of impact on uses of surrounding land and agricultural land, time of reaching leachate to groundwater and pollution by landfills, a good atmosphere and ease of access, lack of contamination of residential areas and the economy in terms of investment in designated areas. Finally, with regard to the practical limitations, expert views and field visits of the most appropriate place for municipal landfill using the PROMETHEE method as a superior option have been selected.

Research conducted by Marcia et al. (2015) obtained similar results as those based on the proper application of the PROMETHEE technique to rank the areas. In another study conducted by Hamzeh et al. (2015), for locating the target, in addition to the ANP method, the PROMETHEE method was used for more accurate modeling of the real world and obtaining better results. Also, Bogusław (Bogusław 2013), in addition to the method used in this study, has used Monte Carlo simulation methods for prioritization of interested places due to the increasing power of decision making and risk mitigation to achieve better results.

In order to create a clean and healthy environment for the citizens, comprehensive management of solid waste collection and disposal is required. The basis of health and hygiene of the cities is their cleanliness; collection and disposal are the most important and influential factors, and they require a proper system of waste management.

A proper waste management cycle includes elements to reduce production, collection, transportation, processing, recycling and disposal from the production point to the landfill; the implementation of each of the above steps requires careful planning and design. One of the things that must be considered in the design of an environmental landfill site is the issue of leachate management and preventing contamination of groundwater. In this study, given that the DRASTIC method is more practical compared to other methods for determining potential aquifer vulnerability, it is used to assess the potential aquifer contamination of leachate from the waste.

The zoning map of aquifer vulnerability of the area under study, which is obtained by incorporating the seven-parameter raster maps of the DRASTIC model with respect to the weight of each parameter in GIS, shows that the parameters of depth of water $(D)$ and net recharge $(R)$ have the highest 
Proper location of landfills

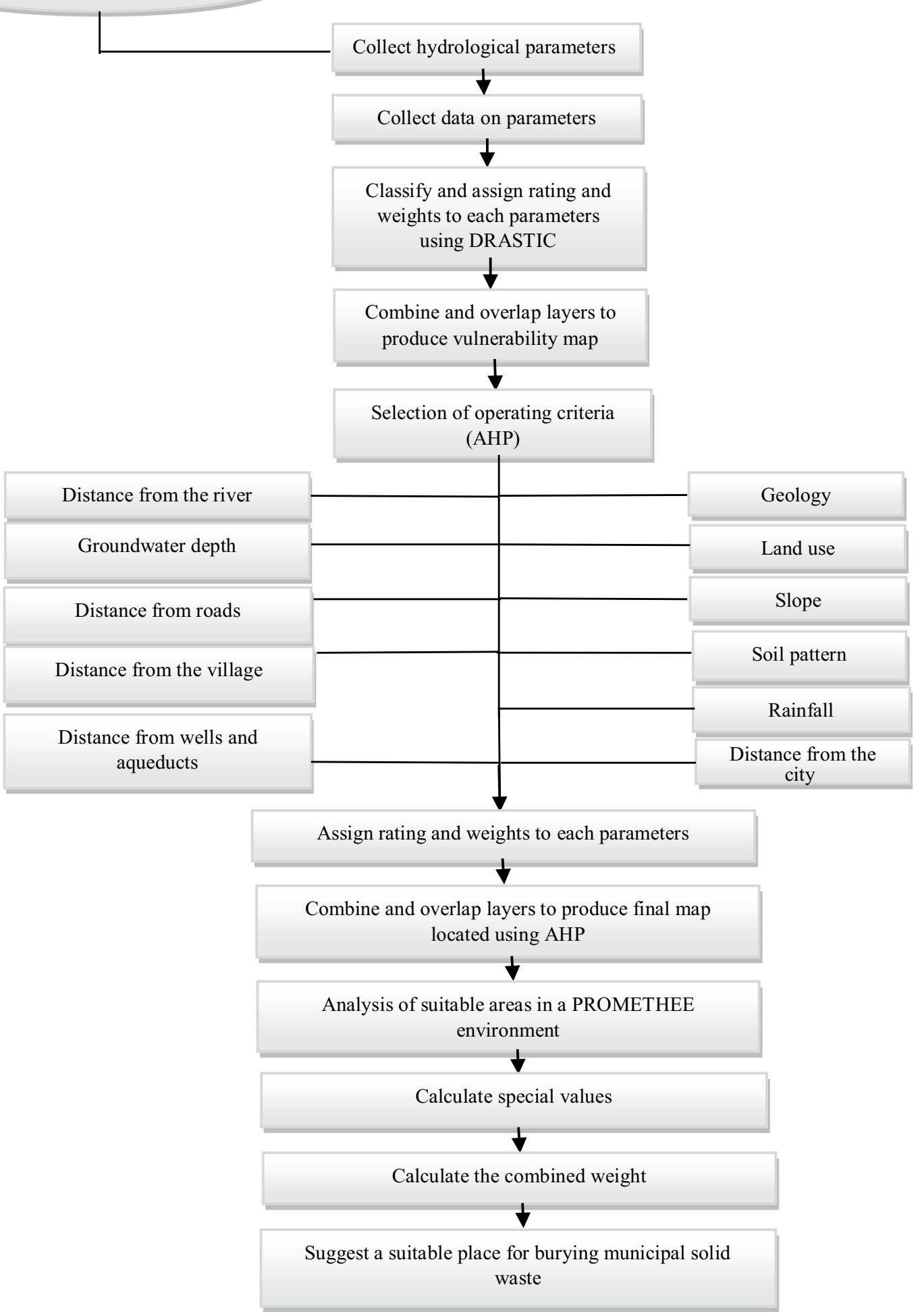

Fig. 26 General algorithm for deciding on a suitable burial site 
Table 16 Vulnerability index, class and corresponding area

\begin{tabular}{llcc}
\hline Vulnerability class & DRASTIC index & Area in $\mathrm{Km}^{2}$ & $\begin{array}{l}\text { Percent- } \\
\text { age of } \\
\text { area }\end{array}$ \\
\hline Low & $82-100$ & 97.29 & 4.25 \\
Moderate & $101-140$ & 1121.07 & 49.03 \\
High & $141-186$ & 1067.99 & 46.71 \\
\hline
\end{tabular}

influence on determining aquifer vulnerability. In the map, it is found that $53 \%$ of the area under study has a low and medium vulnerability, and about $47 \%$ has high vulnerability.

For future works, it is suggested to use other multi-criteria decision-making methods such as TOPSIS, ELECTRE3 and ANP4 and compare the results obtained with this method. Also, when implementing the rules and limitations contained in locating and reviewing the environmental regulations for waste disposal, an appropriate location with more attention to the type of soil and vegetation, groundwater and other local conditions can be chosen.

On the other hand, due to the high volume and extreme extent of the pollution caused by urban waste disposal, the authorities are requested to prevent spread and effective penetration to the environment, soil and natural resources and groundwater caused by pollution by applying timely and appropriate measures, investigation and further study in this field.

\section{Conclusion}

Generally, the approach in this research literature is the first about inappropriate places by GIS in order to identify and eliminate the need for a range of smaller case studies. Considering measures and technical as well as economic, political and social conditions along with existing laws and regulations and using pairwise comparisons, the method to action and to the layers of weight problem was allocated and then a place to bury wastes was mapped.

The map showed three classes and the low as well as the middle classes were divided. So at this stage, we have a smaller number of selected locations. Then, from among the higher classes, we make a choice by the PROMETHEE method. Then, we have the final rankings of the options and the most suitable place to bury the wastes is identified. The PROMETHEE method is a ranking-structured approach to enrich evaluations. The PROMETHEE method's superiority is because it functions in such a way that the decision criteria for selection can be different from the benefits of this approach. In this study, by using the PROMETHEE II method, we attempted to rank places in the higher classes obtained by net flow. The Zanjan
Plains are in arid and semiarid land, which is always facing water shortage.

Hence, groundwater with a high $65 \%$ shares of water supplies the required. So, the necessity of protecting groundwater resources arises. There is a need to strengthen it at the next step of managerial actions in order to exploit the vital resources properly.

According to the results in the most important and widely available subterranean water table in the region as well as in the field identified in the landfills, which is located on the impact of the pollution underground water resources is a vital field is important. The importance of this type of establishment of environmental principles, relocation in the construction of landfills, which requires the assessment of potential vulnerabilities of the project, experts and with high investment, solve this problem. By guiding national and regional centers in the construction and agricultural industries and landfilling while protecting grounwater resources in these areas, the value of investments will increase.

The land units, on the basis of physical characteristics, can help in ranking the soil. The routes selected are areas in Region 1 as they contain important characteristics such as low permeability, dense soil and porosity less than other areas. So, it gets relative priority. Also, they contain the electrical conductivity of arid lands. Land Unit 4 , because of the presence of top soil tissue, has higher permeability than other units. It enjoys the least priority to build a landfill.

Acknowledgements I hereby thank the Zanjan Regional Water Organization and the Department of Agriculture and Natural Resources Research Center of Zanjan for their cooperation in gathering basic information.

Open Access This article is licensed under a Creative Commons Attribution 4.0 International License, which permits use, sharing, adaptation, distribution and reproduction in any medium or format, as long as you give appropriate credit to the original author(s) and the source, provide a link to the Creative Commons licence, and indicate if changes were made. The images or other third party material in this article are included in the article's Creative Commons licence, unless indicated otherwise in a credit line to the material. If material is not included in the article's Creative Commons licence and your intended use is not permitted by statutory regulation or exceeds the permitted use, you will need to obtain permission directly from the copyright holder. To view a copy of this licence, visit http://creativecommons.org/licenses/by/4.0/.

\section{References}

Abdoli M (2005) Recycling of municipal solid wastes. Tehran University, Tehran

Aller L, Bennet T, Lehr JH, Petty RJ, Hackett G (1987) DRASTIC: a standardized system for evaluating groundwater pollution potential using hydro geological settings. EPA, Washington, USA

Al-Rawabdeh AM, Al-Ansari NA, Al-Taani AA, Knutsson S (2013) A GIS-Based DRASTIC model for assessing aquifer vulnerability in Amman-erqa groundwater basin. Jordan Eng J 5(5):490-504 
Awawdeh MM, Jaradat RA (2010) Evaluation of aquifers vulnerability to contamination in the Yarmouk River basin, Jordan, based on DRASTIC method. J Earth Environ Sci 3(3):273-282

Badgie D, Abu Samah MA, Abd ML, Muda AB (2012) (2012) Assessment of municipal solid waste composition in Malaysia: management, practice, and challenges. Pol J Environ Stud 21(3):539-547

Bogusław B (2013) stochastic approach to municipal solid waste landfill life based on the contaminant transit time modeling using the Monte Carlo (MC) simulation. Sci Total Environ 442:489-496

Brans P (1982) Elaboration instruments d'aideà la decision. Method PROMETHEE. In: Nadeau R, Landry M (eds) L'aide à la decision. Nature, Instruments Perspectives d Avenir, Québec, Canada, pp 183-213

Brans J, Mareschal B (1995) The PROMETHEE VI procedure. How to differentiate hard from soft multi criteria problems. J Decis Syst 4:213-223

Chang NB, Parvathinathan G, Breeden JB (2008) Combining GIS with fuzzy multicriteria decision-making for landfill sitting in a fastgrowing urban region. J Environ Manag 87(1):139-153

Donevska KR, Gorsevski P, Jovanovski M, Pesevski I (2012) Regional non-hazardous land fill site selection by integrating fuzzy logic AHP and GIS. Environ Earth Sci 67(1):121-131

El Naqa A (2004) Aquifer vulnerability assessment using the DRASTIC model at Russeifa landfill, northeast Jordan. Environ Geol 47(1):51-62

El-Naqa A, Hammouri N, Kioso M (2006) GIS-based evaluation of groundwater vulnerability in the Russeifa area. Jordan Revista Mexicana de Ciencias Geológicas 23(3):277-287

Hamzeh M, Ali Abbaspour R, Davalou R (2015) Raster-based outranking method: a new approach for municipal solid waste landfill (MSW) sitting. Environ Sci Pollut Res 22:12511

Hasar H, Unsal SA, Ipek U, Karatas S, Cinar O, Yaman C (2009) Stripping/flocculation/membrane bioreactor/reverse osmosis treatment of municipal landfill leachate. J Hazard Mater 171(1-3):309-317

Isalou A, Zamani V, Shahmradi B, Alizadeh H (2012) Landfill site selection using integrated fuzzy logic and analytic network process (F-ANP). Environ Earth Sci 68:1745-1755

Javadi S, Kavehkar N, Mousavizadeh MH, Mohammadi K (2011) Modification of DRASTIC model to map groundwater vulnerability to pollution using nitrate measurements in agricultural areas. J Agric Sci Technol 13:239-249

Kim KR, Owens G (2009) Potential for enhanced phytoremediation of landfills using bio solids-a review. J Environ Manag. https://doi. org/10.1016/j.jenvman.2009.10.017

Manoliadis O, Baronos A, Tsolas I (2001) A two level multicriteria DSS for Landfill Site Selection. Environ Prot Ecol 2(2):45-49

Marcia O, Dalila BMM, Teresa P (2015) Evaluating vehicle painting plans in an automobile assembly plant using an integrated AHPPROMETHEE. Int Transac Oper Res 25:1383-1406

Mareschal B, Brans JP (1988) Geometrical representations for MCDA. The GAIA module. Eur J Oper Res 34:69-77

McNally L (2002) Protection of water resources in landfill sitting in Vietnam. a thesis submitted in multicriteria evaluation techniques and fuzzy logic in sitting MSW landfills. Environ Geol $51: 797-811$

Morrissey AJ, Browne J (2004) Waste management models and their application to sustainable waste management. Waste Manag 24:297-308

Nikoo M, Salari M, Rakhshandehroo GhR (2018) Degrdation of ciprofloxacin antibiotic by homogeneous fenton oxidation: hybrid AHP_PROMETHEE method, optimization, biodegrability improvement and identification of oxidized by products. Chemosphere 206(2018):157-167

Ozkan B, Ozceylan E, Saricicek I (2019) (2019) GIS-based MCDM modeling for landfill site suitability analysis: a comprehensive review of the literature. Environ Sci Pollut Res 26:30711-30730

Ozkan B, Ozceylan E, Saricicek I (2020) GIS-based MCDA with hesitant fuzzy linguistic term sets for landfill site selection. Environ Sci Pollut Res. https://doi.org/10.1007/s11356-020-10128-0

Piscopo G (2001) Ground water vulnerability map, explanatory notes (Castlereagh catchment). NSW Department of Land and Water Conservation, Australia

Rahman A (2008) A GIS based DRASTIC model for assessing groundwater vulnerability in shallow aquifer in Aligarh, India. Appl Geogr 28:32-53

Saaty L (1980) The analytic hierarchy process: planning, priority setting resource allocation. McGraw-Hill, New York, NY, p 437

Saaty L, Vargas LG (1991) prediction projection and forecasting. Kluwer Academic Publishers, Dordrecht, p 251

Salimi M, Ebrahim A, Salimi A (2014) Aquifer vulnerability assessment using the DRASTIC model at new landfill site in Isfahan. J Health Syst Res 1(2):395-405

Sener S, Sener E, Karaguzel R (2011) Solid waste disposal site selection with GIS and AHP methodology: a case study in Senirkent-Uluborlu (Isparta) Basin. Turk Environ Monit Assess 173:533-554

Stigter TY, Ribeiro L, Carvalho Dill AMM (2006) Evaluation of an intrinsic and a specific vulnerability assessment method in comparison with groundwater salinization and nitrate contamination level in two agriculture regions in the south of Portugal. J Hydrogeol 14(1-2):79-99

Sulaiman H, Kabite G, Suryabhagaran KV, Argaw M (2012) GISbased waste landfill site selection in Addis Ababa, Ethiopia. Int Ecol Environ Sci 38(2-3):59-72

Sumathi R, Natesan U, Sarkar C (2008) GIS-based approach for optimized sitting of municipal solid waste landfill. Waste Manag 28:2146-2160

Ying X, Guang-Ming Z, Gui-Qiu C, Lin T, Ke-Lin W, Dao-You H (2007) Combining AHP with GIS in synthetic evaluation of ecoenvironment quality - a case study of Hunan Province, China. Ecol Model 209(2-4):97-109

Zamorano M, Molero E, Hurtado A, Grindlay A, Ramos A (2008) Evaluation of a municipal landfill site in Southern Spain with GIS-aided methodology. J Hazard Mater 160(2e3):473e481 